\section{Oxidation of Gaseous Formaldehyde}

IN a recent communication to Nature on this subject, J. M. Thomas and $I^{1}$ described some experimental results which showed that in a 'matured' quartz vessel at $320^{\circ} \mathrm{C}$ direct oxidation of formaldehyde by oxygen to hydrogen peroxide occurred to the very considerable extent of 70 per cent:

$$
\mathrm{HCHO}+\mathrm{O}_{2}=\mathrm{H}_{2} \mathrm{O}_{2}+\mathrm{CO}
$$

In a reaction vessel newly treated with nitric acid or hydrofluoric acid, however, the production of hydrogen peroxide was minimal and not greater than 2 per cent, the main products being water and carbon monoxide:

$$
\mathrm{HCHO}+\frac{1}{2} \mathrm{O}_{2}=\mathrm{H}_{2} \mathrm{O}+\mathrm{CO}
$$

During a recent discussion in Moscow it was pointed out to me that very similar results had already been reported by Markewich and Filippova ${ }^{2}$ and by Markewich and Pecherskaya ${ }^{3}$ between 1957 and 1961, in which they showed that reaction (1) occurs to the extent of about 27 per cent in glass or quartz vessels "matured" after treatment with chromic acid, while with vessels treated with a 2 per cent solution of potassium borate $\left(\mathrm{K}_{2} \mathrm{~B}_{4} \mathrm{O}_{7}\right)$, the reaction takes the second course represented by equation (2). Markewich and Pecherskaya ${ }^{3}$ also proposed a chain reaction similar to the one which we proposed.

There cannot be the slightest doubt that full priority accrues to Markewich et al., and I wish to express our regret to them for failing to acquaint ourselves with their work and, as a consequence, omitting reference to their publications.

Department of Physical Chemistry,

$$
\text { R. G. W. NORRISH }
$$

University of Cambridge.

${ }^{1}$ Norrish, R. G. W., and Thomas, J. M., Nature, 210, 728 (1966).

${ }^{2}$ Markewieh, A. M., and Filippova, L. F., Zhur. Fiz. Khim., 31, 2649 (1957) 33, 2214 (1959).

${ }^{3}$ Markewich, A. M., and Pecherskaya, Yu. I., Zhur. Fiz. Khim., 35, 1418 (1961).

\section{Neutralization of Hydronium lons in the Radiolysis of Water Vapour}

WHEN water vapour is irradiated, the main primary positive ion is $\mathrm{H}_{2} \mathrm{O}^{+}$and it may be assumed that the reaction:

$$
\mathrm{H}_{2} \mathrm{O}^{+}+\mathrm{H}_{2} \mathrm{O} \rightarrow \mathrm{H}_{3} \mathrm{O}^{+}+\mathrm{OH}
$$

$\left(k_{1}=1.26 \times 10^{-9} \mathrm{~cm}^{3}\right.$ molecules $\left.{ }^{-1} \mathrm{sec}^{-1}\right)$ will result in the formation of hydronium ions ${ }^{1}$. It has been suggested ${ }^{2,3}$ that neutralization of the hydronium ion by recombination with electrons can lead to the formation of two hydrogen atoms per ion:

$$
\mathrm{H}_{3} \mathrm{O}^{+}+e^{-} \rightarrow 2 \mathrm{H}+\mathrm{OH}
$$

but there has been no evidence available to decide between this process and the alternative:

$$
\mathrm{H}_{3} \mathrm{O}^{+}+e^{--} \rightarrow \mathrm{H}+\mathrm{H}_{2} \mathrm{O}
$$

giving one hydrogen atom per ion. In an investigation of the radiolysis of mixtures of deuterium oxide and propane, we have obtained results which have a bearing on this question.

Mixtures, prepared by distilling weighed, deaerated deuterium oxide $(99 \cdot 8$ per cent) samples and known volumes of propane (Phillips Research Grade) into 'Pyrex' vessels $(400 \mathrm{ml}$.), were irradiated with cobalt-60 $\gamma$-rays at $137^{\circ}$. The nitrous oxide dosimeter was used (assuming $\left.G\left(\mathrm{~N}_{2}\right)=12 \cdot 0\right)$ and the dose-rates in deuterium oxide and propane calculated assuming stopping powers per molecule relative to nitrous oxide of $0 \cdot 46$ and $\mathbf{1} \cdot 25$, respectively.

Fig. I shows $G(\mathrm{HD})_{t}$ (molecules of deuterium hydride per $100 \mathrm{eV}$ absorbed by the mixture of deuterium oxide and propane) as a function of the fraction of energy absorbed in deuterium oxide and in propane, for mixtures with propane concentrations from 2 to 98 mole per cent $G(\mathrm{HD})_{w}=8 \cdot 0 \pm 0.5$ and $G(\mathrm{HD})_{p}=4 \cdot 6 \pm 0 \cdot 4$ (mole- cules per $100 \mathrm{eV}$ absorbed in deuterium oxide and propane, respectively) are obtained by extrapolation to zero concentrations of propane and deuterium oxide. The results are consistent with the assumption that $G(\mathrm{HD})_{w}$ and $G(\mathrm{HD})_{p}$ are constant over the whole range of concentration (Fig. 1).

The observed $G(\mathrm{HD})_{w}=8.0 \pm 0.5$ is in reasonable agreoment with the hydrogen atom yield from water and deuterium oxide $\left(G_{H}=G_{D}=7 \cdot 5 \pm 0 \cdot 7\right)$ obtained by Baxendale and Gilbert ${ }^{4,5}$ using methanol as scavenger. Hydrogen was also formed from mixtures of deuterium oxide and propane, $G\left(\mathrm{H}_{2}\right)_{p}=6 \cdot 0 \pm 0 \cdot 5$ being independent of the concentration of propane.

The observed $G(\mathrm{HD})_{p}$ cannot be explained by assuming that the exchange reaction:

$$
\mathrm{H}+\mathrm{D}_{2} \mathrm{O} \rightarrow \mathrm{D}+\mathrm{HDO}
$$

occurs since the propane would compete with deuterium oxide for any hydrogen atoms formed from propane and this would be expected to result in a dependence of $G(\mathrm{HD})_{p}$ and of $G\left(\mathrm{H}_{2}\right)_{p}$ on the concentration of propane. Charge-transfer, from the hydrocarbon positive ions to deuterium oxide, may also be excluded, on energetic grounds.

The observed $G(\mathrm{HD})_{p}$ may be interpreted in terms of proton-transfer from hydrocarbon positive ions to deuterium oxide:

$$
R \mathrm{H}^{+}+\mathrm{D}_{2} \mathrm{O} \rightarrow R+\mathrm{HD}_{2} \mathrm{O}^{+}
$$

where $R \mathrm{H}^{+}$represents the positive ion or ions from propane which undergo proton-transfer. The main positive ions may be assumed to be $\mathrm{C}_{3} \mathrm{H}_{8}{ }^{+}$and $\mathrm{C}_{3} \mathrm{H}_{7}{ }^{+}$, since ions of smaller mass can undergo hydride ion transfer with propane $^{6, ?}$. The proton transfer reaction (5), where $\mathrm{RH}^{-}=$ $\mathrm{C}_{3} \mathrm{H}_{8}{ }^{+}$, has been observed in the mass-spectrometer ${ }^{1,8}$, and is reported to have a rate constant of about $2 \times$ $10^{-9} \mathrm{~cm}^{3}$ molecules ${ }^{-1} \mathrm{sec}^{-1}$ (ref. 8). Proton transfer from $\mathrm{C}_{3} \mathrm{H}_{7}{ }^{+}$to deuterium oxide is exothermic if the proton affinity of deuterium oxide is similar to that of water $\left(\geqslant 154 \mathrm{kcal} / \mathrm{mole}^{-1}\right.$ ) (ref. 9).

It may be assumed that equilibrium:

$$
\mathrm{HD}_{2} \mathrm{O}^{+}+\mathrm{D}_{2} \mathrm{O} \rightleftharpoons \mathrm{D}_{3} \mathrm{O}^{+}+\mathrm{HDO}
$$

will be established rapidly and that the majority of positive ions undergoing neutralization will be the species $\mathrm{D}_{3} \mathrm{O}^{+}$. (There is evidence that the hydronium ions will be clustered at the pressures used, since at pressures as

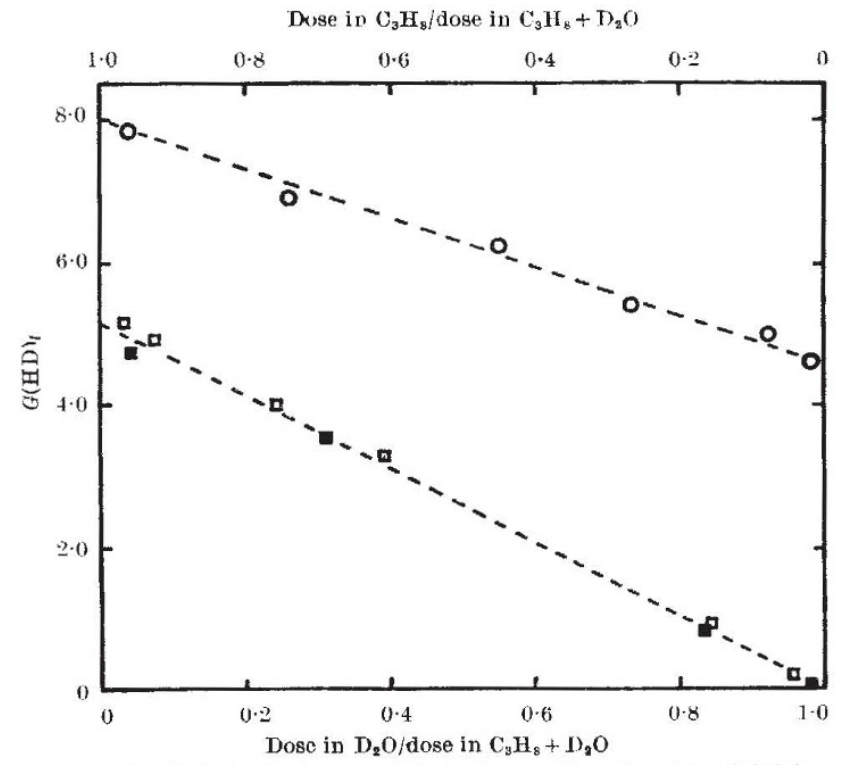

Fig. 1. Radiolysis of mixtures of deuterium oxide and propane $\left(137^{\circ} \mathrm{C}\right.$, density $0 \cdot 8-2 \cdot 7 \mathrm{~g} \mathrm{l}$.). $O, G(\mathrm{HD})_{\text {, }}$ (molecules per $100 \mathrm{eV}$ absorbed in

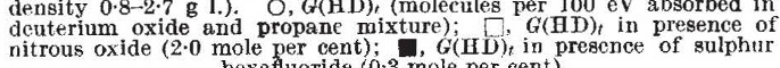

